\title{
Immobilization and Purification of Enzymes With the Novel Affinity Tag ChBD-AB From Chitinolyticbacter meiyuanensis SYBC-H1
}

\author{
Jie Zhou ${ }^{1}$, Jianhao Chen ${ }^{1}$, Nisha Zhuang ${ }^{1}$, Alei Zhang ${ }^{1,2}$, Kequan Chen ${ }^{1,2}$, Ning Xu', \\ Fengxue Xin ${ }^{1,2}$, Wenming Zhang ${ }^{1,2}$, Weiliang Dong ${ }^{1,2 *}$ and Min Jiang ${ }^{1,2}$ \\ 'State Key Laboratory of Materials-Oriented Chemical Engineering, College of Biotechnology and Pharmaceutical \\ Engineering, Nanjing Tech University, Nanjing, China, ${ }^{2}$ Jiangsu National Synergetic Innovation Center for Advanced \\ Materials, Nanjing Tech University, Nanjing, China
}

\section{OPEN ACCESS}

Edited by:

Wen-Yong Lou,

South China University of Technology,

China

Reviewed by:

Zhiming Rao,

Jiangnan University, China

Lirong Yang,

Zhejiang University, China

*Correspondence:

Weiliang Dong

dw@njtech.edu.cn

Specialty section:

This article was submitted to

Bioprocess Engineering,

a section of the journal

Frontiers in Bioengineering and

Biotechnology

Received: 21 March 2020

Accepted: 12 May 2020

Published: 12 June 2020

Citation:

Zhou J, Chen J, Zhuang N,

Zhang A, Chen K, Xu N, Xin F,

Zhang $W$, Dong $W$ and Jiang $M$

(2020) Immobilization and Purification of Enzymes With the Novel Affinity Tag

ChBD-AB From Chitinolyticbacter

meiyuanensis SYBC-H1.

Front. Bioeng. Biotechnol. 8:579.

doi: 10.3389/fbioe.2020.00579
A new protein immobilization and purification system has been developed based on the improved plasmid vectors, designated PETChBD-X, which contained the gene coding for two novel chitin-binding domains ChBD-AB, factor Xa cleavage site and adapted for gene fusions. The ChBD-AD from Chitinolyticbacter meiyuanensis SYBC-H1 was used as a novel affinity tag to anchor fusion proteins to chitin granules. The granules carrying the ChBD-AD fusion proteins can be isolated by a simple centrifugation step and used directly for some applications. Moreover, when required, a practically pure preparation of the soluble recombination protein can be obtained after Factor Xa cleavage. The efficiency of this system has been demonstrated by reaching $95 \%$ of protein absorbed to chitin within 30 min and recycling over $75 \%$ of interest protein after Factor Xa cleavage to separate interest protein and fusion tag. Furthermore, 65\% L-glutamate oxidase with this fusion tag could be purified and immobilized within only one step and to be reused in converting L-glutamate to $\alpha$-ketoglutaric acid directly, the average conversion rate kept above $65 \%$ even within four batches of enzyme conversion reaction.

Keywords: chitin-binding domain, fusion tag, affinity chromatography, protein purification, protein immobilization, enzyme conversion

\section{INTRODUCTION}

Chromatography is an important biological technique used for separating, identifying, and purifying target proteins from a mixture based on different characteristics such as size and shape, total charge, hydrophobic groups present on the surface and so on (Coskun, 2016). Nowadays, a variety of chromatography methods are widely applied in various occasions where protein purification or immobilization are required. Thus, by fusing the coding sequence of the interest protein with different tag sequences, which have high affinity to a ligand, these protein can be efficiently purified for identification and characterization (Li et al., 2017).

Protein affinity tag is an indispensable tool for recombinant protein expression and purification. The invention and application of these fusion tags including C-myc, HA, FLAG, poly-arginine or histidine, streptavidin binding tag, et al., have undoubtedly facilitated the in-depth research and practical application of various proteins (Jin and Amarasinghe, 2015). However, traditional affinity chromatography methods are always high cost and cumbersome operation, thus it appears important to develop new affinity chromatography methods to overcome these shortcomings. 
Carbohydrate-binding module (CBM) including $\mathrm{ChBD}$ is found extensively in glycoside hydrolases, it is a sort of noncatalytic domain performing carbohydrate-binding activity and promoting the association of the enzyme with the substrate (Boraston et al., 2004). In view of high absorbing capacity to substrate, CBM proteins show potential application in feed industry, biomedicine, environmental protection and molecular biology (Oliveira et al., 2015). Recently, CBMs have been developed as useful affinity tags applied in purification and immobilization of proteins. For example, Rodriguez et al. (2004) used cellulose binding-domain as affinity tag and the purity of target protein reached over 95\%; Demishtein et al. (2010) used a modified CBM as affinity tag and finally recovered about $90 \%$ of target protein; Liao et al. (2012) reported an example of one-step purification and immobilization of thermophilic polyphosphate glucokinase by using a family 3 cellulose-binding domain as fusion tag; Qin et al. (2019) realized one-step immobilization and purification of enzymes by carbohydratebinding module family 56 tag fusion. All the examples above concluded that CBMs are practical and reliable fusion tags which have great potential for applications in biology research. When being used as affinity tags, CBMs usually possess two obvious advantages: high specificity and low cost. In general, the ability of binding specific substrates is unique to CBM, this uniqueness can prevent non-specific binding of other protein. In addition, the substrates which can bind CBMs, such as cellulose, chitin, xylan, starch and so on, are usually low-cost because of their widespread in nature.

In this work, we successfully truncated two potential chitin-binding domains (ChBD-AB) of chitinase CmChil from Chitinolyticbacter meiyuanensis SYBC-H1 according to amino acid analysis and confirmed its affinity ability to chitin which may be valuable in applying as fusion tag (Zhang et al., 2018). We constructed a novel protein immobilization and purification system with these $\mathrm{ChBD}-\mathrm{AB}$, and the universal plasmid vector ( $\mathrm{pETChBD}-\mathrm{X}, \mathrm{X}$ represents gene encoding interest protein) contained the gene coding the two novel chitinbinding domains ChBD-AB, factor Xa cleavage site has been improved. The usefulness of these vector were exemplified by fusions to the typical genes encoding green fluorescent protein (GFP) and L-glutamate oxidase (LGOX). The visible purifying process and efficiency of purification and immobilization were evaluated. One-step immobilized L-glutamate oxidase (LGOX) in converting L-glutamate to $\alpha$-ketoglutaric acid $(\alpha-K G)$ directly were established. This may provide a useful purification and immobilization platform for researching and application of recombinant proteins.

\section{MATERIALS AND METHODS}

\section{Reagents and Strains}

Chitin powder was purchased from Sinopharm Chemical Reagent, Co. (Beijing, China). Molecular biological reagents including DNA polymerase and restriction enzymes (Nde I, Xho I) purchased from TaKaRa Biotechnology, Co. (Dalian, China). Exnase required for one step cloning was purchased from Vazyme Biotech, Co. (Nanjing, China). Relevant molecular reagents kits including bacteria genomic DNA kit, plasmid miniprep kit, gel mini purification kit and SDS-PAGE kit were purchased from Zoman Biotechnology, Co. (Beijing, China).

The lysogeny broth (LB) contained $10 \mathrm{~g} / \mathrm{L}$ tryptone, $5 \mathrm{~g} / \mathrm{L}$ yeast extract, and $5 \mathrm{~g} / \mathrm{L} \mathrm{NaCl}$. Expression vector pET-29a were used to fusion target gene fragments while Escherichia coli BL21 (DE3) was used as host strain in this work. All strains were cultivated in LB medium.

\section{Plasmid and DNA Manipulations}

The ChBD-AB gene, which was encoding two ChBDs modules of chitinase $C m$ Chil, was amplified by polymerase chain reaction (PCR) from genome of Chitinolyticbacter meiyuanensis SYBC$\mathrm{H} 1$ and a fragment encoding factor Xa cleavage site was added at the primer. The PCR reactions were performed for 32 cycles $\left(95^{\circ} \mathrm{C}\right.$ for $30 \mathrm{~s}, 60^{\circ} \mathrm{C}$ for $30 \mathrm{~s}, 72^{\circ} \mathrm{C}$ for $\left.90 \mathrm{~s}\right)$, followed by a 10 min extension at $72^{\circ} \mathrm{C}$. Then the amplified PCR products were purified and ligated into the pET29a vector. This way, one universal plasmid vector $\mathrm{pETChBD}-\mathrm{X}$ was generate (Figure 2).

Then, the gene fragments encoding GFP and LGOX respectively were inserted multi clone site (MCS) by one step cloning for further study. After transformation into E. coli $\mathrm{DH} 5 \alpha$, the positive transformants were screened and verified by DNA sequencing. plasmid pETChBD-GFP and pETChBD-LGOX with a C-terminal His 6-tag were obtained. The recombinant plasmid was transformed into competent E. coli BL21(DE3) for protein expression. Sequencing service was supplied by GenScript Biotech Co. (Nanjing, China).

\section{Overexpression and Purification of Proteins}

Escherichia coli BL21(DE3) harboring pETChBD-X, pETChBDGFP, and pETChBD-LGOX were inoculated into LB medium containing kanamycin at final concentration of $50 \mathrm{mg} / \mathrm{L}$ and incubated at $37^{\circ} \mathrm{C}$ with a rotation speed of $180 \mathrm{rpm}$. After the optical density $\left(\mathrm{OD}_{600}\right)$ of the culture broth reached 0.6-0.8, isopropyl $\beta$-D-thiogalactopyranoside (IPTG) was added to a final concentration of $1 \mathrm{mM}$, and the culture was further grown at $20^{\circ} \mathrm{C}$ and with a rotation speed of $120 \mathrm{rpm}$ for $24 \mathrm{~h}$.

The bacterial cells were harvested by centrifugation at $2124 \times g$ and $4^{\circ} \mathrm{C}$ for $10 \mathrm{~min}$, washed twice with equilibration buffer $(20 \mathrm{mM}$ Tris- $\mathrm{HCl}$ buffer, $\mathrm{pH} 7.0)$ at $4^{\circ} \mathrm{C}$ and then disrupted by ultrasonication. After, the cell debris was removed by centrifugation at $12,580 \times g$ and $4^{\circ} \mathrm{C}$ for $20 \mathrm{~min}$, and the supernatant was retained as crude extract. The target recombinant proteins $\mathrm{ChBD}-\mathrm{AB}$ was purified by $\mathrm{Ni}$ NTA agarose column. Sodium dodecyl sulfate-polyacrylamide gel electrophoresis (SDS-PAGE) was carried out to analyze purification steps of the target proteins using standard methods.

\section{Preparation of Ultrasonic Wave Chitin Powder and Colliodial Chitin}

Ultrasonic wave chitin powder (UWCP) was prepared by ultrasonic crusher previously described. $20 \mathrm{~g} / \mathrm{L}$ of chitin powder suspension was treated by sonication, the parameters were set 


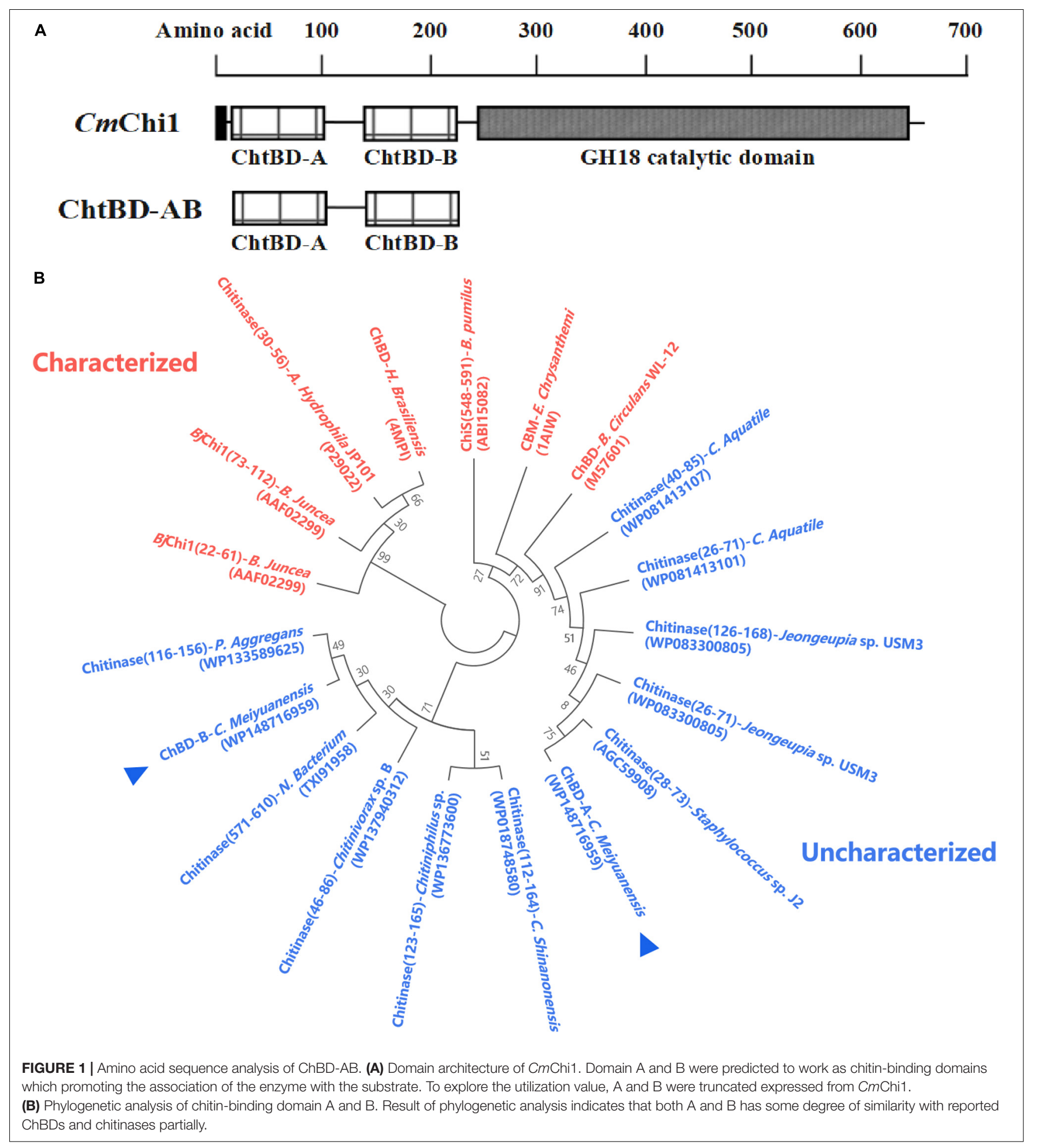

to $25 \mathrm{kHZ}, 300 \mathrm{~W}$ for $20 \mathrm{~min}$. During the whole process, the suspension was cooled with ice water.

The preparation of colloidal chitin (CC) was referred to Inokuma et al. (2013) method. $10 \mathrm{~g}$ chitin powder was soaked by $40 \mathrm{~mL}$ acetone for $2 \mathrm{~min}$ and then been mixed with $100 \mathrm{~mL}$ concentrated hydrochloric acid (35\%). The mixture were stirred with magnetic stirrer until it became transparency and then pored into $2000 \mathrm{~mL}$ cold ethanol (50\%). After being fully stirred, the solution was left in the refrigerator overnight at $4^{\circ} \mathrm{C}$ with $100 \mathrm{~mL}$ of $35 \%$ hydrochloric acid. The mixture was stirred with magnetic stirrer until it became transparency and then pored into $2000 \mathrm{~mL}$ cold ethanol. Repeat the above steps and 


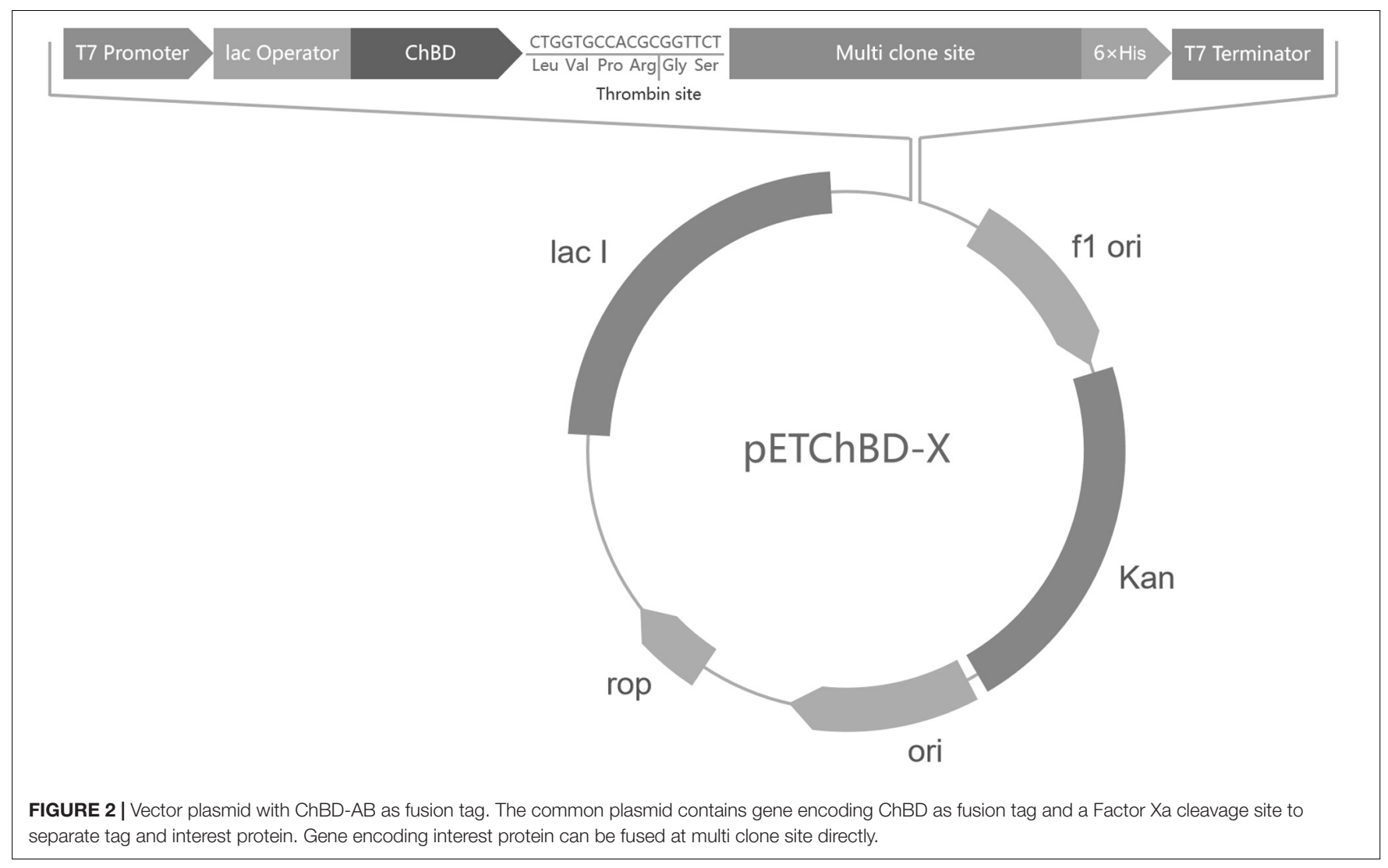

TABLE 1 | Orthogonal experiments of binding.

\begin{tabular}{|c|c|c|c|c|c|}
\hline & \multicolumn{4}{|c|}{ Factors } & \multirow{2}{*}{$\begin{array}{l}\text { Absorption } \\
\text { rate }\end{array}$} \\
\hline & Absorbent & Time & Concentration & Temperature & \\
\hline 1 & $1(\mathrm{CP})$ & 1 (15 min) & $1(20 \mathrm{~g} / \mathrm{L})$ & $1\left(4^{\circ} \mathrm{C}\right)$ & $72.94 \%$ \\
\hline 2 & 1 & 2 (30 min) & $2(30 \mathrm{~g} / \mathrm{L})$ & $2\left(10^{\circ} \mathrm{C}\right)$ & $90.47 \%$ \\
\hline 3 & 1 & 3 (60 min) & $3(40 \mathrm{~g} / \mathrm{L})$ & $3\left(20^{\circ} \mathrm{C}\right)$ & $90.47 \%$ \\
\hline 4 & 2 (UWCP) & 1 & 2 & 3 & $94.74 \%$ \\
\hline 5 & 2 & 2 & 3 & 1 & $91.04 \%$ \\
\hline 6 & 2 & 3 & 1 & 2 & $90.24 \%$ \\
\hline 7 & 3 (CC) & 1 & 3 & 2 & $73.49 \%$ \\
\hline 8 & 3 & 2 & 1 & 3 & $80.56 \%$ \\
\hline 9 & 3 & 3 & 2 & 1 & $75.54 \%$ \\
\hline $1 / 3$ & 84.627 & 80.390 & 81.247 & 79.840 & \\
\hline $11 / 3$ & 92.007 & 87.357 & 86.917 & 84.733 & \\
\hline $111 / 3$ & 76.530 & 85.417 & 85.000 & 88.590 & \\
\hline $\mathrm{R}^{\mathrm{a}}$ & 15.477 & 6.967 & 5.670 & 8.750 & \\
\hline
\end{tabular}

rinse colloidal chitin for several times until the $\mathrm{pH}$ value of the resuspension was around 6.0. Finally, colloidal chitin was prepared at $1 \%$ concentration.

\section{Chitin-Binding Assay}

Chitin was added to solution containing purified ChBD-AB protein, then the suspension was incubated under different conditions. After the adsorption was completed, solid was removed by centrifugation. Residual protein concentration in supernate was detected. In this way, the adsorption rates were calculated as follows:

Adsorption rate $=\left(1-\frac{\text { Protein quality in supernate }}{\text { Initial protein quality }}\right) \times 100 \%$.

Detection of protein concentration was referred to Bradford method (Campion et al., 2017). Four factors were taken into account to investigate the effects on absorption: material of adsorbent, temperature, adsorbent concentration and incubating time. Four principal factors are systematically examined using orthogonal design of experiments (L9 matrix) based on the results of single-factor experiments, different experiments were designed according to different conditions and factors were independent and non-interference. Statistical analysis was used to identify the order of principal factors in terms of adsorption rates. Results including optimal condition and impact level of different factors were analyzed using MINITAB 14 software (Wu and Leung, 2011).

With regards to ChBD-GFP and ChBD-LGOX, lysates were used directly for adsorption under the optimal condition and the absorption effects were detected by SDS-PAGE. The absorption rate of ChBD-GFP was characterized by measuring the quality of GFP which was converted from the fluorescence intensity (Cha and Kwon, 2018) and absorption rate here was calculated as the above formula. The fluorescence intensity was detected by 


\section{Immbilization}

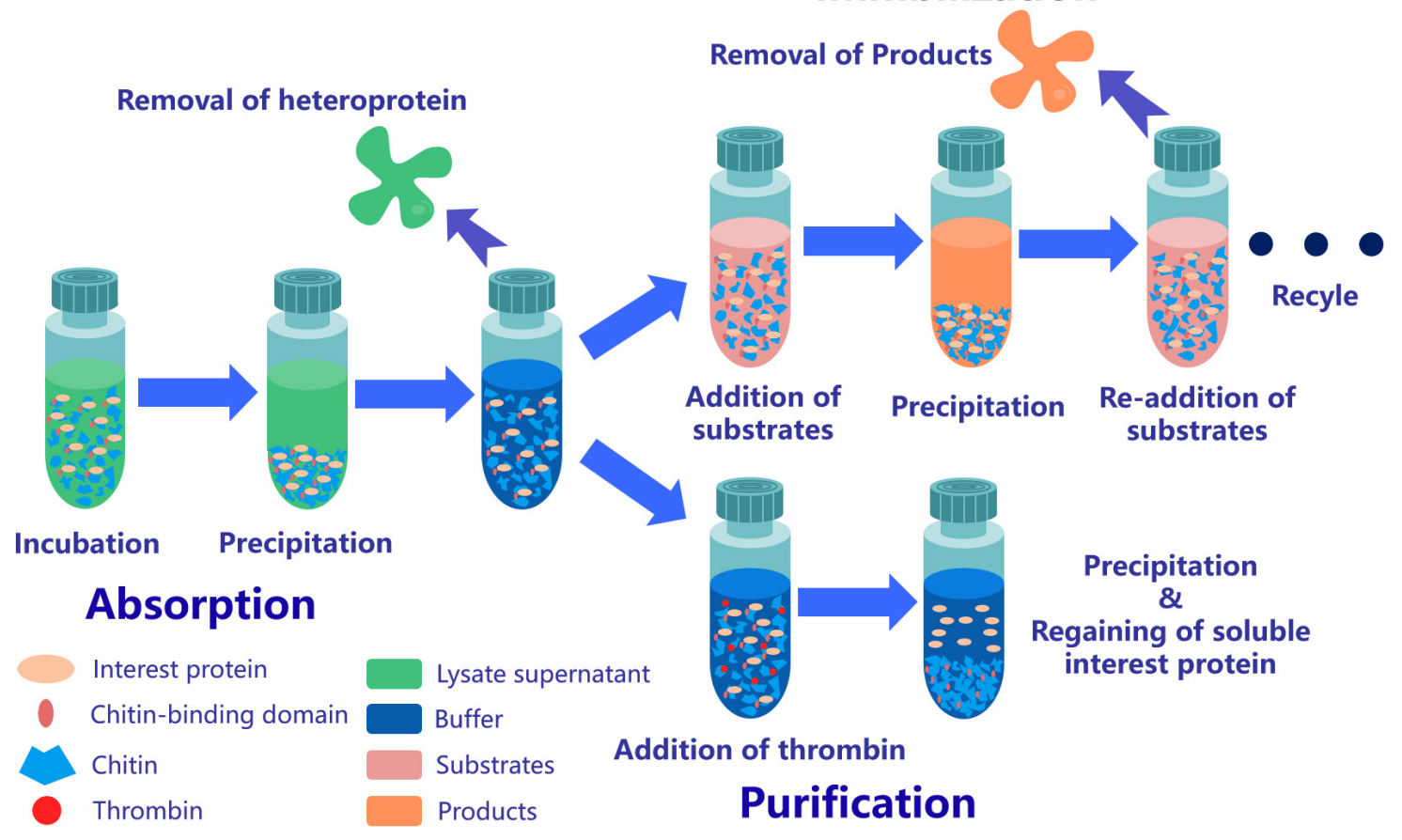

FIGURE 3 | Application strategy of affinity chromatography system based on ChBD-AB. Interest protein fused ChBD can be absorbed by chitin on the purpose of separation from impurities. Obtained absorbed protein is able to be applied in repeating enzymatic conversion reaction or resolve into buffer through Factor Xa site cleavage.

Hitachi F7000 fluorescence spectrophotometer. The absorption rate of ChBD-LGOX was characterized by measuring the activity of LGOX to quantitatively analyze the absorption effect of recombinant enzyme. The absorption rate was characterized by enzyme activity and was calculated as follows:

$$
\text { Adsorption rate }=\left(\frac{\text { LGOX activity in absorbent }}{\text { Initial LGOX activity }}\right) \times 100 \% \text {. }
$$

One unit of LGOX activity was defined as the amount of enzyme that released $1 \mu$ mol $\mathrm{H}_{2} \mathrm{O}_{2}$ per minute. LGOX activity was measured by using a 4 -aminoantipyrine method (Niu et al., 2014). The optimum catalytic conditions of different LGOX were determined under standard activity conditions using several buffers with various $\mathrm{pH}$ and temperature. The thermalstability and $\mathrm{pH}$-stability of free and immobilized LGOX are determined under standard activity conditions after enzyme being incubated at different conditions for $30 \mathrm{~min}$, and the residual activity was determined. All binding assays above were carried out at the condition of optimal $\mathrm{pH}$ of chitinase $\mathrm{CmChi1}$ (Zhang et al., 2018). All measurements were taken in triplicate and experiments were repeated three times to evaluate the standard deviation.

\section{Elution of GFP Protein From UWCP}

Chitin loaded with immobilized GFP was suspended again by phosphate buffer solution (PBS) and right amount of Factor-Xa $\quad(0.2 \sim 0.3 \quad \mathrm{U} / 100 \quad \mu \mathrm{g}$ interest protein) was added. After incubation at $4^{\circ} \mathrm{C}$ for one night, the insoluble was separated by centrifugation while target protein was retained in the supernatant. The recovery rate was calculated as follows:

$$
\text { Recovery rate }=\left(\frac{\text { GFP quality in suspension }}{\text { Initial GFP quality }}\right) \times 100 \% .
$$

\section{Production of $\alpha-K G$ by Transformation of L-Glutamic Acid via Immobilized LGOX}

The enzymatic conversion adopted an optimized condition: $110 \mathrm{~g} / \mathrm{L}$ L-glutamate, $1.5 \mathrm{U} / \mathrm{mL}$ immobilized LGOX and $250 \mathrm{U} / \mathrm{mL}$ catalase, which was used for removing $\mathrm{H}_{2} \mathrm{O}_{2}$ and its toxicity, in each batch of reaction (Niu et al., 2014). At the end of each batch of reaction, the product and the enzyme will be separated by centrifugation. After repeating the above steps for several times, the product concentration was determined by high performance liquid chromatography (HPLC) against a $\alpha$ KG standard using a calibration curve, and then the $\alpha-K G$ yield from L-glutamate was calculated.

\section{RESULTS}

\section{Analysis of Putative ChBDs From CmChi1}

Amino acid sequence analysis revealed that $C m$ Chil encoded two chitin-binding modules named module $\mathrm{A}$ and $\mathrm{B}$, respectively 
(Figure 1A), and both A and B belong to ChBD3 family which is widely existing in chitinases. The main structure of ChBD3 family domain is a discrete $\beta$-sandwiche and several short $\alpha$-helixes between $\beta$-sandwiche providing a site for substrate binding (Vaaje-Kolstad et al., 2010). Multiple amino acid secquence alignments of the two domains revealed that ChBD-A show only $40.4 \%$ identity with ChBD of Chitinase A1 from Bacillus circulans WL-12 (Hashimoto et al., 2000; Ferrandon et al., 2003). The ChBD-AB show high similarity with some chitinases which have not been biochemically characterized according to phylogenetic analysis (Figure 1B). These results demonstrated that the ChBD-AB of $\mathrm{CmChil}$ are novel ChBDs which have potential value for research and application.

\section{Parameter Optimization of Chitin-Binding Activity of ChBD-AB}

The recombinant protein $\mathrm{ChBD}-\mathrm{AB}$ with a $\mathrm{C}$-terminal $6 \times \mathrm{His}$ tag was successfully expressed and purified by Ni-NTA. SDSPAGE results showed that there were obvious specific bands same with purified proteins in the lanes with chitin matrix in chitin-binding assay (Figure 4). This phenomenon indicated that heterogenous expressed protein $\mathrm{ChBD}-\mathrm{AB}$ performed great abilities of binding chitin.

Four different factors were investigated including adsorption materials, temperature, absorbent concentration and incubating time. According to experimental data, UWCP performed best activity for binding protein $\mathrm{ChBD}-\mathrm{AB}$ as the absorption rate reached $68 \%$ in 30 min while that of $C$ C and $C P$ were 58 and $25 \%$, respectively (Figure 5A). For UWCP performed best in binding essay, it was used as absorbent for further optimization. The effects of temperature on adsorption efficiency was investigated. The ChBD-AB protein and UWCP were mixed and incubated at 4,10 , and $20^{\circ} \mathrm{C}$ respectively. For reducing the potential damage to target protein, temperature beyond $20^{\circ} \mathrm{C}$ is not considered in here. Absorption rate at 4 and $10^{\circ} \mathrm{C}$ was similar about $43 \%$. When the temperature went up to $20^{\circ} \mathrm{C}$, the adsorption rate increased significantly to $68 \%$. Obviously, the best absorption rate was at $20^{\circ} \mathrm{C}$ (Figure 5B).

As shown in Figure 5C, protein ChBD-AB performed best level of absorption rate reached $66 \%$ at $30 \mathrm{~g} / \mathrm{L}$ UWCP. When the concentration rised up from 10 to $30 \mathrm{~g} / \mathrm{L}$, the absorption rate rised up from 43 to $66 \%$ simultaneously. Nonetheless, the absorption rate decreased rapidly to $48 \%$ as the concentration of UWCP rised up to $40 \mathrm{~g} / \mathrm{L}$. Absorption rate was also assayed by incubation of protein $\mathrm{ChBD}-\mathrm{AB}$ with UWCP for different incubation time. As shown in Figure 5D, the velocity of adsorption decreased significantly in 5 to $60 \mathrm{~min}$, and the absorption rate reached $81 \%$ at $60 \mathrm{~min}$. In this case, the usual experience is to choose the fastest growing stage of adsorption within $60 \mathrm{~min}$.

After that, orthogonal experiments be further used for optimization of Chitin-binding activity of ChBD-AB. Experimental parameters here were set according to the results of single factor experiments. There were nine experiments to optimize binding condition. Among these experiments, the best absorption conditions were $30 \mathrm{~g} / \mathrm{L} \mathrm{UWCP}$, at $20^{\circ} \mathrm{C}$ for $15 \mathrm{~min}$ with a highest absorption rate as $94.74 \%$ (Table 1). Further data

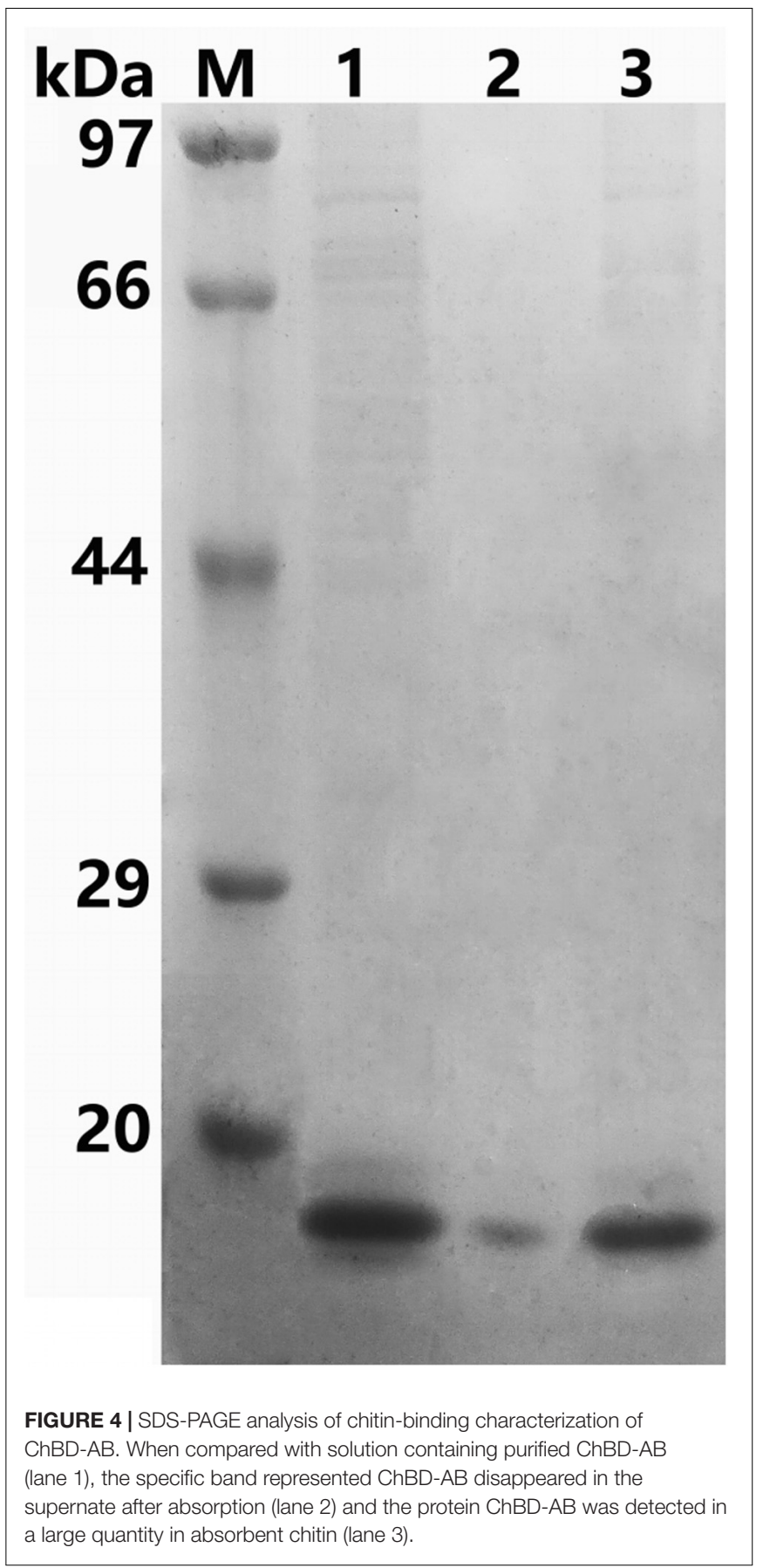

analysis identified the optimum conditions was $30 \mathrm{~g} / \mathrm{L} \mathrm{UWCP}$, at $20^{\circ} \mathrm{C}$ for $30 \mathrm{~min}$ when the absorption rate could reach over $95 \%$.

\section{Visible Protein Purification Process}

After incubation of ChBD-GFP and UWCP, ChBD-GFP was recovered after Factor-Xa cleavage (Figure 3). These results demonstrated the whole purification process clearly (Figure 6). And the absorption rate was detected as $91.03 \%$ through the conversion of fluorescence intensity to quality, every gram UWCP was observed at a total loading of $3055 \mu \mathrm{g}$ protein 

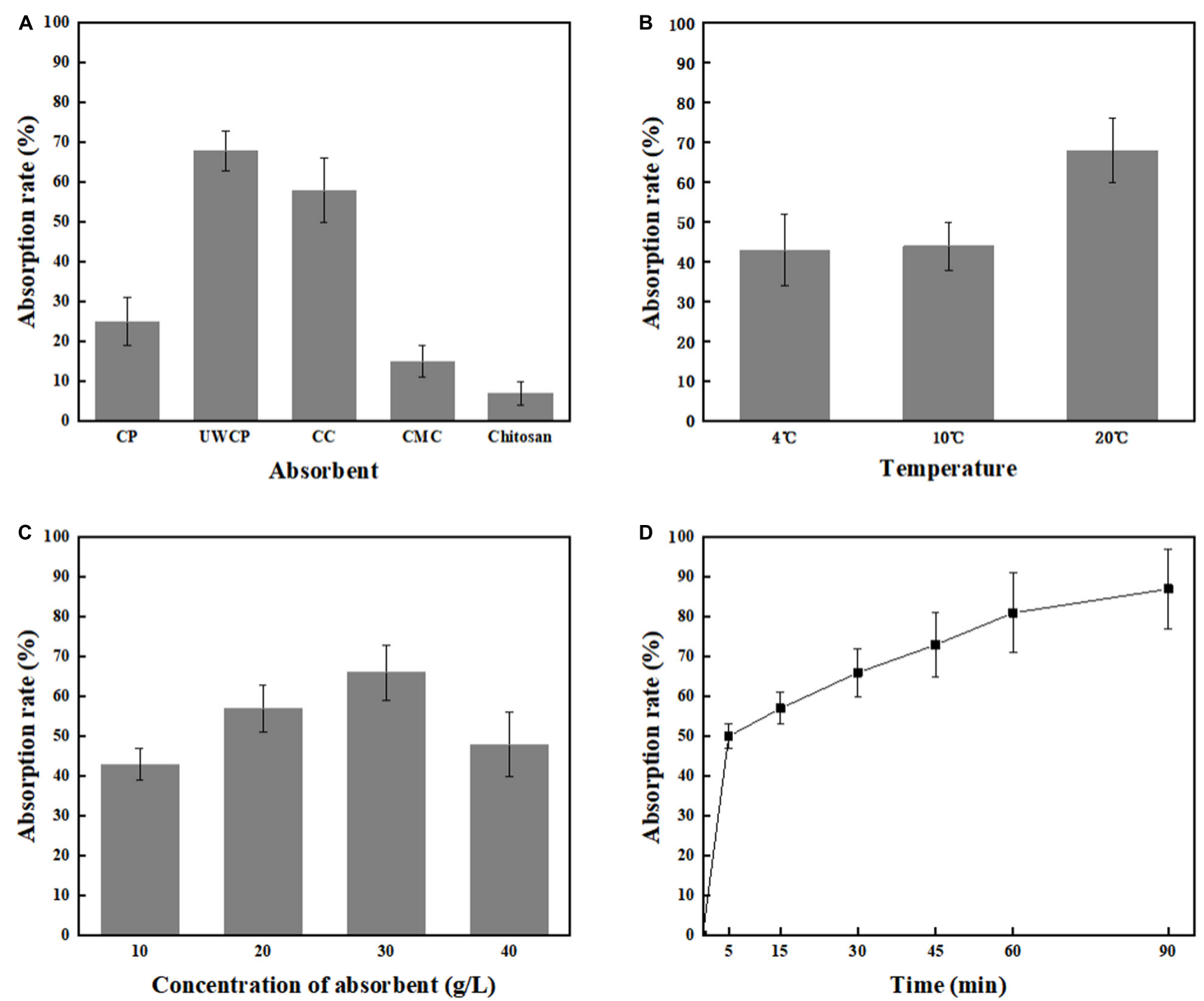

FIGURE 5 | Single factor optimization of binding. (A) Impact of absorbent on binding. (B) Impact of temperature on binding. (C) Impact of concentration of absorbent on binding. (D) Impact of time on binding.

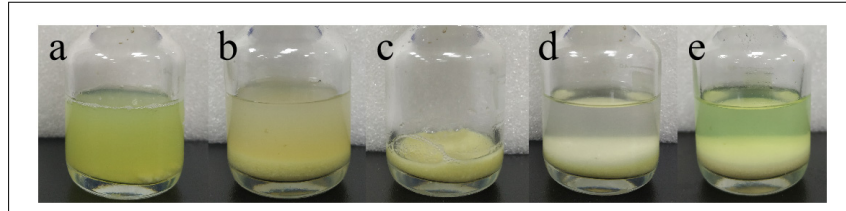

FIGURE 6 | Visible purification process of GFP. (a) Cell lysate containing interest protein. (b) Cell lysate after interest protein absorbed by chitin.

(c) Absorbent chitin with immobilized interest protein. (d) Buffer and

absorbent chitin with immobilized interest protein before thrombin digestion.

(e) Buffer and absorbent chitin after thrombin digestion.

(Table 2). After digestion using Factor Xa, totally $75.05 \%$ of GFP without ChBD was recovered while the supernatant finally changed to clear green (Figure 6). SDS-PAGE analysis also
TABLE 2 | Purification process of recombinant GFP.

\begin{tabular}{lccc}
\hline & Volume $(\mathbf{m L})$ & $\begin{array}{c}\text { Quality of interest } \\
\text { protein }(\boldsymbol{\mu} \mathbf{g})\end{array}$ & $\begin{array}{c}\text { Recovery } \\
\text { yield (\%) }\end{array}$ \\
\hline Lysate & 30 & 3019.99 & 100 \\
Precipitate & 30 & 4749.21 & 91.03 \\
Supernatant & 30 & 2280.25 & 75.05 \\
\hline
\end{tabular}

showed the high efficiency of purification and purity of target protein (Figure 7).

\section{One-Step Immobilization and Repeated Use of LOGX}

ChBD-LGOX show strong ability to bind UWCP, and the process of purification and immobilization can be simplify 


\section{$\begin{array}{llllll}\mathrm{kDa} & \mathrm{M} & 1 & 2 & 3 & 4\end{array}$}

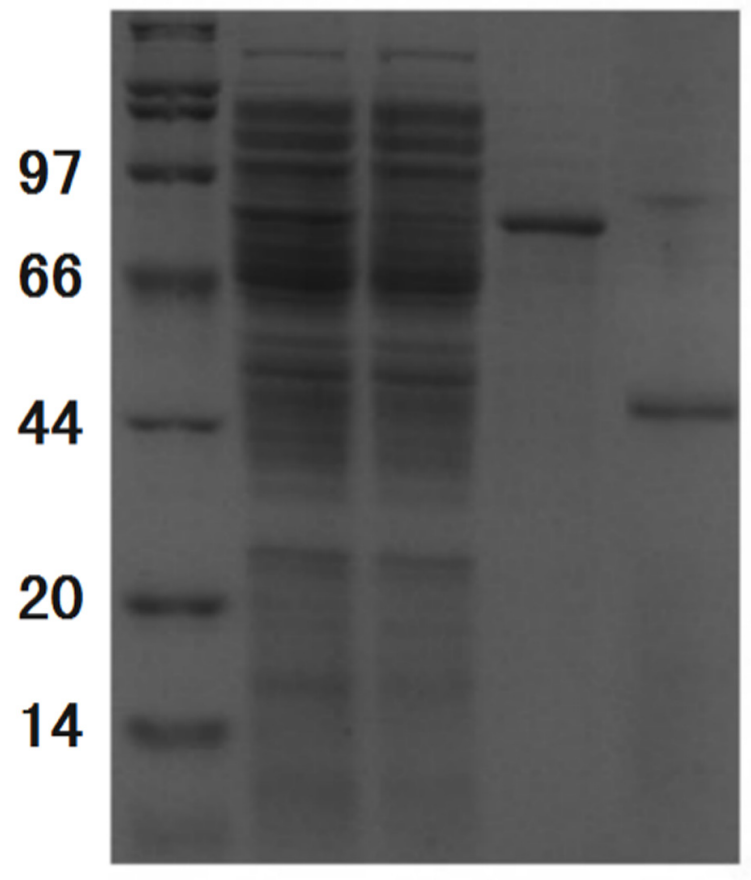

FIGURE 7 | SDS-PAGE analysis of purification process of GFP. Band of interest protein ChBD-GFP disappeared in cell lysate after binding (lane 2) when compared with cell lysate before binding (lane 1), the majority of interest protein was retained in precipitate (lane 3). After thrombin digestion, GFP without $\mathrm{ChBD}$ could be resolved in buffer with high purity (lane 4).

to one step (Figure 3). According to the enzyme activity assay, high amounts of intact fusion protein are obtained with a $65 \%$ of absorption rate. Meanwhile the immobilized

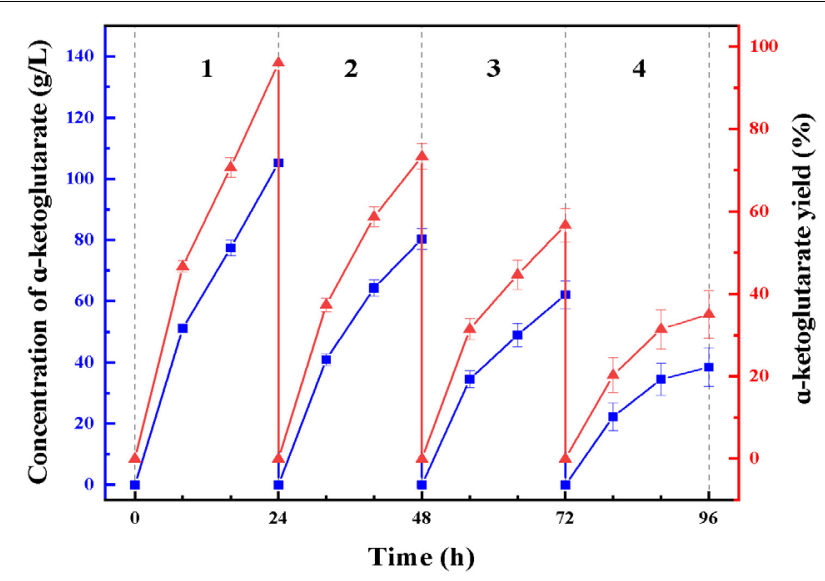

FIGURE 9 | Repeating use of LOGX in enzymatic conversion of $\alpha-K G$. Imobilized LGOX fused with ChBD could be reused in converting L-glutamate to $\alpha$-ketoglutaric acid directly. Experiments show that this method is feasible as expected.

ChBD-LGOX showed much better thermal and $\mathrm{pH}$ stability than free enzyme (Figure 8).

At enzymatic conversion assay of L-glutamate to $\alpha$-ketoglutaric acid, the immobilized ChBD-LGOX showed relatively good reusability. The highest titer of $-\mathrm{KG}$ reached $105 \mathrm{~g} / \mathrm{L}$ from $110 \mathrm{~g} / \mathrm{L}$ L-glutamic acid, with conversion ratio 96\% within $24 \mathrm{~h}$ at the first batch (Figure 9). However, the conversion rate of ChBD-LGOX decreased significantly at subsequent batches, and the conversion ratio remained of only $35 \%$ after four batches. We speculated that the yield of repeating enzymatic conversion decreased may due to the loss enzyme activity, which was consistent with the results of temperature stability (Figure 8B).
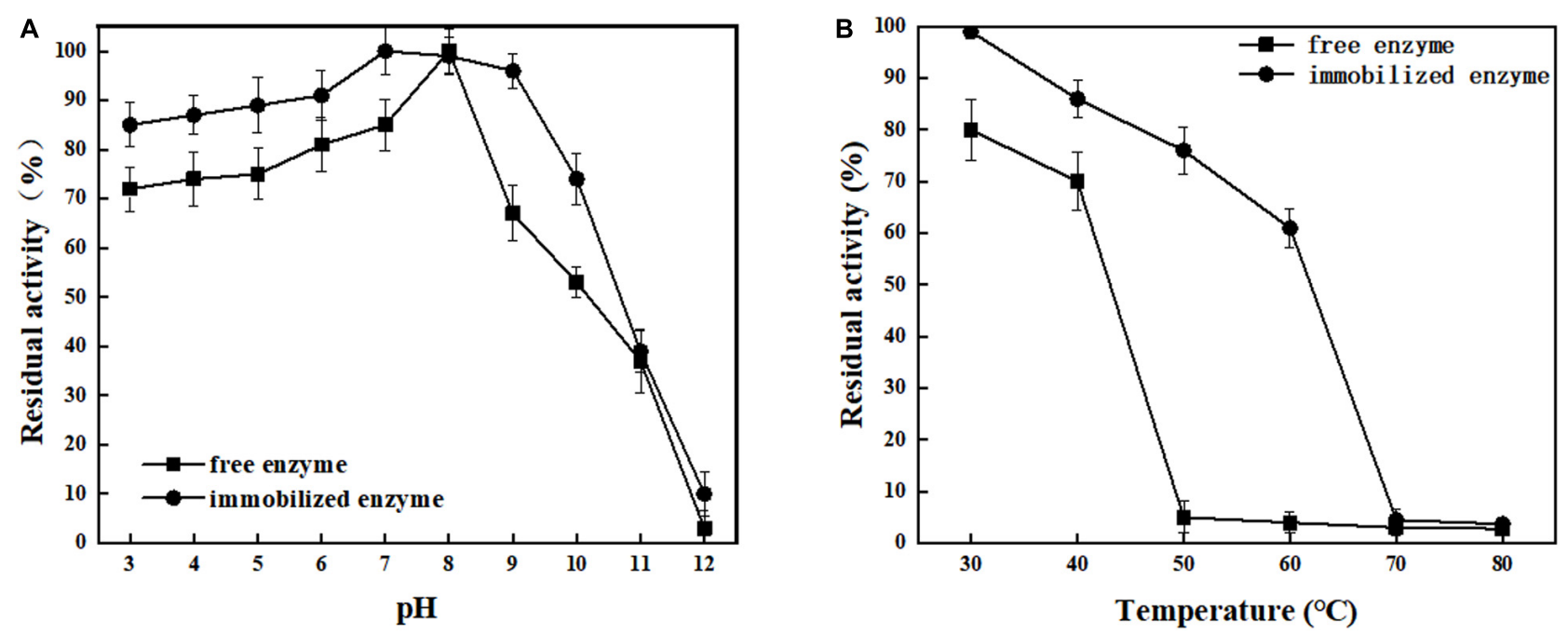

FIGURE 8 | Stability analysis of immobilized and free LOGX. (A) pH stability. (B) Thermal stability. Immobilized enzyme showed much better stability than free enzyme. 


\section{DISCUSSION}

This paper described the construction of a universal fusion vectors $\mathrm{pETChBD}-\mathrm{X}$ allowing expression of fusion proteins which can be affinity purified by a one-step procedure. The purification is based on novel ChBD-AB tag of CmChil which under physiological conditions binds to cheap chitin waste. After parameter optimization, the optimal binding condition was $30 \mathrm{~g} / \mathrm{L}$ UWCP and incubating at $20^{\circ} \mathrm{C}$ for $30 \mathrm{~min}$. These conditions are very advantageous for recombinant protein purification. Firstly, chitin is a kind of absolutely non-polluting material as it is natural. Secondly, the time, cooling and reagent costs will be further compressed by optimization. Generally speaking, many reported cases of protein purification based on carbohydrate-binding domain usually need overnight incubating such as Myung et al. (2011) immobilized phosphoglucose isomerase through cellulose-binding moduletagged thermophilic enzyme which took a lot of time to incubate. The operation at $20^{\circ} \mathrm{C}$ was near room temperature and operation process can be greatly simplified with adsorption and centrifugation. For example, Ramirez et al. (2013) used a CBM as fusion tag to immobilize endo-b- $N$-acetylglucosaminidase and the system should be incubated at $4^{\circ} \mathrm{C}$ which increased thermal insulation costs greatly. What's more, the price of chitin is very low and the preparing process of UWCP is relatively simple as well. Thirdly, the whole process of purification or immobilization is simple, only incubation and centrifugation are needed.

By all accounts, the protein purification and immobilization method provided in this study is suitable for large-scale industrial application because of its unique advantages. Recombinant protein ChBD-GFP also showed good bonding property, 91\% interest was absorbed under the same condition and $75 \%$ was recovered after factor-Xa digestion. The visualization process intuitively reflects these steps and SDS-AGE analysis confirmed the high-purity of interest protein. Recovery yield data is much higher than reported cases, for instance, Leister applied chitin-binding domain in immobilizing $\beta$-galactosidases and received activity retention of 55\% (Leister, 2014); Ramirez et al. (2013) immobilized pectinase on an alginate-coated chitin support by adsorption and the yield of immobilized protein was $70 \%$ and the enzyme retained $60 \%$ of the initial activity.

Another recombinant protein ChBD-LGOX was successfully purified and immobilized in single step which revealed the convenience of this method. High amounts of intact fusion protein are produced which can be immobilized on UWCP in a yield (65\%). Moreover, the stability of enzyme was significantly enhanced after immobilization. This is consistent with some reported cases, for example, the cis-epoxysuccinate hydrolases fused with cellulose-binding domain and immobilized on cellulose showed better stability than its wild-type version (Cui et al., 2012); Chern and Chao (2005) immobilized D-allantoinase by using chitin-binding domain from Bacillus circulans WL-12, the active half-life of immobilized enzyme was greatly prolonged. The characterization of ChBD-LGOX changed especially the enzymatic activity decreased by a big margin which revealed an obvious disadvantage of this immobilization approach. Stereospecific blockade between fusion tag and target protein might be the main reason for this phenomenon, further research is needed to overcome this shortage. When applied in enzymatic conversion, the immobilized enzyme also showed good value, average conversion rate kept above $65 \%$ even within four batches of conversion reaction, averagely $72 \mathrm{~g} / \mathrm{L} \alpha$-ketoglutarate could be produced from $110 \mathrm{~g} / \mathrm{L}$ L-glutamate. Though the yield was relatively low when compared with reported cases, such as Ödman et al. (2004) Used a coupled system Lglutamate dehydrogenase/NADH oxidase to convert nearly $100 \%$ L-glutamateto to $\alpha$-ketoglutarate, the most significant advantage of the enzymatic conversion method in this study is that immobilized enzyme could be used repeatedly. Although the yield of repeating enzymatic conversion decreased by a big margin, this is mainly due to the relatively poor stability of the enzyme itself. Thus, the recombinant enzyme ChBD-LGOX may after all be accepted as an appropriate tool for producing $\alpha$-ketoglutarate with energy saving and low consumption.

\section{CONCLUSION}

In summary, the $\mathrm{ChBD}-\mathrm{AB}$ affinity tag system described here provides a novel tool for an innovative alternative method for purifying, immobilizing, and spreading fusion proteins. Great advantages including low cost, no pollution, easy operation, rapidness, and high-purity suggested that the plasmid vector $\mathrm{pETChBD}-\mathrm{X}$ has potential value in immobilization and purification of enzymes.

\section{DATA AVAILABILITY STATEMENT}

The raw data supporting the conclusions of this article will be made available by the authors, without undue reservation.

\section{AUTHOR CONTRIBUTIONS}

JZ was responsible for experimental design and thesis writing. JC and NZ were responsible for experimental operation. AZ and KC provided experimental materials. NX, FX, WZ, MJ, and WD contributed to data analysis and polishing thesis.

\section{FUNDING}

This work was financially supported by the National Key R\&D Program of China (No. 2018YFA0902200), National Natural Science Foundation of China (Nos. 31961133017, 21978129, and 21908102), Jiangsu Province Science Foundation for Youths (Nos. BK20170997 and 20170993), Jiangsu Agriculture Science and Technology Innovation Fund (No. CX(19)3104), and Project of State Key Laboratory of Materials-Oriented Chemical Engineering (No. ZK201601). 


\section{REFERENCES}

Boraston, A. B., Bolam, D. N., and Gilbert, H. J. (2004). Carbohydrate-binding modules: fine-tuning polysaccharide recognition. Biochem. J. 382, 769-781. doi: 10.1042/BJ20040892

Campion, E. M., Loughran, S. T., and Walls, D. (2017). "Protein quantitation and analysis of purity," in Protein Chromatography, eds D. Walls and S. Loughran (Totowa, NJ: Humana Press), 229-258.

Cha, J., and Kwon, I. (2018). Purification-free, target-selective immobilization of a protein from cell lysates. Biotechnol. J. 13, 322. doi: 10.1002/biot.201700739

Chern, J. T., and Chao, Y. P. (2005). Chitin-binding domain based immobilization of D-hydantoinase. J. Biotechnol. 117, 267-275. doi: 10.1016/j.jbiotec.2005. 02.001

Coskun, O. (2016). Separation techniques: chromatography. Nort. Clin. Ista. 3, 156-160. doi: 10.14744/nci.2016.32757

Cui, G. Z., Wang, S., Li, Y., Tian, Y. J., Feng, Y., and Cui, Q. (2012). High yield recombinant expression, characterization and homology modeling of two types of cis-epoxysuccinic acid hydrolases. Protien J. 31, 432-438. doi: 10.1007/ s10930-012-9418-5

Demishtein, A., Karpol, A., Barak, Y. R., Lamed, R., and Bayer, E. A. (2010). Characterization of a dockerin-based affinity tag: application for purification of a broad variety of target proteins. J. Mol. Rec. 23, 525-535. doi: 10.1002/jmr. 1029

Ferrandon, S., Sterzenbach, T., Mersha, F. B., and Xu, M. Q. (2003). A single surface tryptophan in the chitin-binding domain from Bacillus circulans chitinase A1 plays a pivotal role in binding chitin and can be modified to create an elutable affinity tag. Biochim. Biophys. Acta 1621, 31-40. doi: 10.1016/S0304-4165(03) 00029-1

Hashimoto, M., Ikegami, T., Seino, S., Ohuchi, N., Fukada, H., Sugiyama, J., et al. (2000). Expression and characterization of the chitin-binding domain of chitinase A1 from Bacillus circulans WL-12. J. Bacteriol. 182, 3045-3054. doi: 10.1128/JB.182.11.3045-3054.2000

Inokuma, K., Takano, M., and Hoshino, K. (2013). Direct ethanol production from $\mathrm{N}$-acetylglucosamine and chitin substrates by Mucor species. Biochem. Eng. J. 72, 24-32. doi: 10.1016/j.bej.2012.12.009

Jin, J. P., and Amarasinghe, C. (2015). The use of affinity tags to overcome obstacles in recombinant protein expression and purification. Protien Pept. Lett. 22, 885-892. doi: 10.2174/0929866522666150728115307

Leister, T. (2014). Immobilization of $\beta$-Galactosidase from Lactobacillus Delbrueckii subsp. Bulgaricus Using Chitin-Binding Domain and Biochemical Characterization of Immobilized Enzyme for Lactose Hydrolysis. Doctoral dissertation, University of Natural Resources and Life Sciences, Vienna.

Li, Z., Rodriguez, E., Azaria, S., Pekarek, A., and Hage, D. S. (2017). Affinity monolith chromatography: a review of general principles and applications. Electrophoresis 38, 2837-2850. doi: 10.1002/elps.201700101

Liao, H., Myung, S., and Zhang, Y. H. P. (2012). One-step purification and immobilization of thermophilic polyphosphate glucokinase from Thermobifida fusca YX: glucose-6-phosphate generation without ATP. Appl. Microbiol. Biotechnol. 93, 1109-1117. doi: 10.1007/s00253-011-3458-1
Myung, S., Zhang, X. Z., and Percival, Z. Y. H. (2011). Ultra-stable phosphoglucose isomerase through immobilization of cellulosebinding module-tagged thermophilic enzyme on low-cost high-capacity cellulosic adsorbent. Biotechnol. Prog. 27, 969-975. doi: 10.1002/ btpr.606

Niu, P., Dong, X., Wang, Y., and Liu, L. (2014). Enzymatic production of $\alpha$-ketoglutaric acid from L-glutamic acid via L-glutamate oxidase. J. Biotechnol. 179, 56-62. doi: 10.1016/j.jbiotec.2014. 03.021

Ödman, P., Wellborn, W. B., and Bommarius, A. S. (2004). An enzymatic process to $\alpha$-ketoglutarate from l-glutamate: the coupled system L-glutamate dehydrogenase/NADH oxidase. Tetrahedron Asymmetry 15, 2933-2937. doi: 10.1016/j.tetasy.2004.07.055

Oliveira, C., Carvalho, V., Domingues, L., and Gama, F. M. (2015). Recombinant CBM-fusion technology - Applications overview. Biotechnol. Adv. 33, 358369. doi: 10.1016/j.biotechadv.2015.02.006

Qin, Z., Lin, S., Qiu, Y., Chen, Q., Zhang, Y., Zhou, J., et al. (2019). Onestep immobilization-purification of enzymes by carbohydrate-binding module family 56 tag fusion. Food Chem. 299:125037. doi: 10.1016/j.foodchem.2019. 125037

Ramirez, H. L., Briones, A. I., Úbeda, J., and Arevalo, M. (2013). Immobilization of pectinase by adsorption on an alginate-coated chitin support. Biotechnol. Apl. 30, 101-104.

Rodriguez, B., Kavoosi, M., Koska, J., Creagh, A. L., Kilburn, D. G., and Haynes, C. A. (2004). Inexpensive and generic affinity purification of recombinant proteins using a family 2a CBM fusion tag. Biotechnol. Prog. 20, 1479-1489. doi: 10.1021/bp0341904

Vaaje-Kolstad, G., Westereng, B., and Horn, S. J. (2010). An oxidative enzyme boosting the enzymatic conversion of recalcitrant polysaccharides. Science 330, 219-222. doi: 10.1126/science. 1192231

Wu, X., and Leung, D. (2011). Optimization of biodiesel production from camelina oil using orthogonal experiment. Appl. Ener. 88, 3615-3624. doi: 10.1016/j. apenergy.2011.04.041

Zhang, A., He, Y., and Wei, G. (2018). Molecular characterization of a novel chitinase CmChil from Chitinolyticbacter meiyuanensis SYBC-H1 and its use in N-acetyl-d-glucosamine production. Biotechnol. Biofuels 11:179. doi: 10.1186/ s13068-018-1169-x

Conflict of Interest: The authors declare that the research was conducted in the absence of any commercial or financial relationships that could be construed as a potential conflict of interest.

Copyright (c) 2020 Zhou, Chen, Zhuang, Zhang, Chen, Xu, Xin, Zhang, Dong and Jiang. This is an open-access article distributed under the terms of the Creative Commons Attribution License (CC BY). The use, distribution or reproduction in other forums is permitted, provided the original author(s) and the copyright owner(s) are credited and that the original publication in this journal is cited, in accordance with accepted academic practice. No use, distribution or reproduction is permitted which does not comply with these terms. 